\title{
ASSESSMENT OF MITRAL REGURGITATION BY DYE DILUTION CURVES
}

\author{
BY \\ LEON RESNEKOV \\ From the Cardiac Department, King's College Hospital *
}

Received March 13, 1961

Hering $(1829,1832)$ obtained circulation times by detecting injected samples of potassium ferrocyanide by the Prussian Blue reaction, as quoted by Dow (1956). Stewart (1894) extended the work of Hering and was able to measure the cardiac output by a quantitative determination of the dilution of a solution of salt injected intravenously. It has taken many years since Stewart's time for the indicator dilution technique to become clinically accepted, and this is but an indication of the many problems that had first to be solved, not least amongst which has been the improvement of recording devices.

This paper deals with the assessment of mitral regurgitation by the indirect indicator technique with special reference to the Shillingford Index (Shillingford, 1958).

Coomassie Blue was chosen as the indicator. The properties, biological behaviour and clinical applications of this blue azo dye have been fully dealt with by Taylor and Thorp (1959) and Taylor and Shillingford (1959), who found it eminently suitable as an indicator dilution substance. The dye is relatively non-toxic and does not cause staining of the skin. It can be extracted readily by the urea and acetone method of Clausen and Lifson (1956). The dye remains wholly intravascular by being bound to the serum proteins, is metabolized by reductive fission of the azo link, and is mainly excreted in the urine, although a large concentration is found in the bile. The rate of clearing from the intravascular space falls between the very rapid Indigo Carmine and the very slow Evans Blue (T-1824).

In our experience the dye has proved very satisfactory. In over 400 injections in all types of heart disease we have had only three toxic reactions. All three were in adults who had received more than $500 \mathrm{mg}$. by serial injections. In two patients it gave rise to nausea and vomiting; the remaining case had a profound fall in systemic pressure. It is our practice now to limit the total dose of the drug to $400 \mathrm{mg}$., using the 2 per cent solution in preference to the 4 per cent, which is liable to precipitate.

\section{PRINCIPLES}

The basic principles of the indicator dilution technique are, briefly, that following an injection of dye into either a peripheral vein or chamber of the heart there is an interval known as the appearance time (Fig. 1) which represents the time from the point of injection to the site of sampling. Then follows a rapid rise in concentration to a maximum rounded peak. A slower progressive fall in concentration next occurs until the fall-off slope is interrupted by a peak of secondary circulation which indicates a volume of dye that has been once round the circulation and has returned to the sampling site. The tail of the curve then gradually flattens to a straight line which represents the

\footnotetext{
* Present address, The National Heart Hospital and Institute of Cardiology, London, W.1.
} 


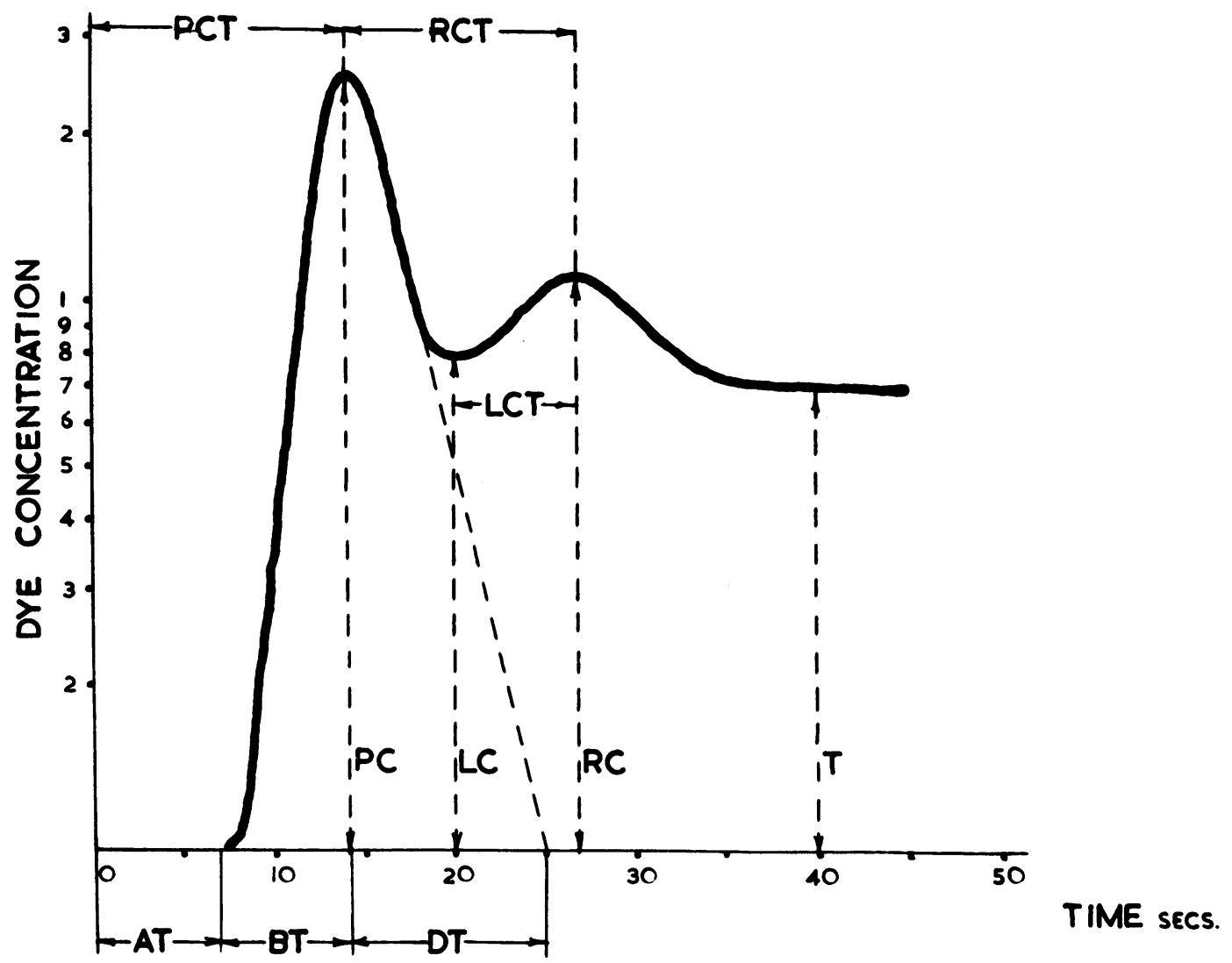

FIG. 1.-Normal Dye Dilution Curve

A.T.: Appearance Time. B.T.: Build-up Time. D.T.: Disappearance Time. L.C.: Least Concentration. L.C.T.: Time of Least Concentration. P.C.: Peak Concentration. P.C.T.: Time of Peak Concentration. R.C.: Peak of Systemic Re-circulation. R.C.T.: Time of Peak of Systemic Re-circulation. T.: Concentration of Tail of Curve.

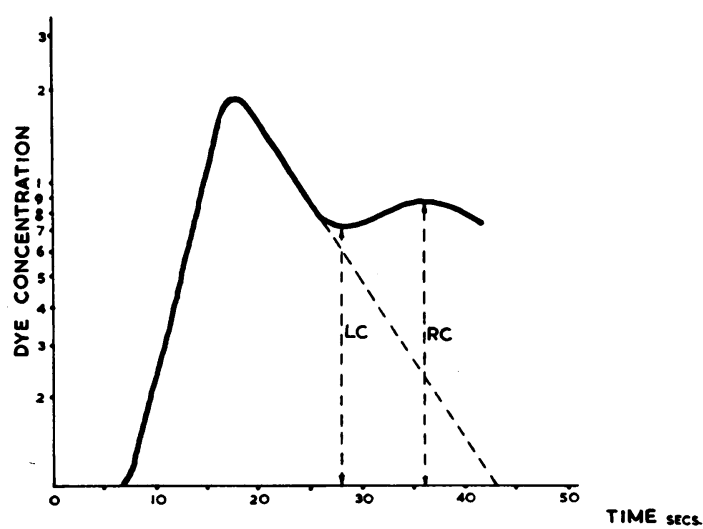

Fig. 2.-Degree of mitral incompetence assessed by the ratio of the least concentration (L.C.) to peak systemic re-circulation (R.C.) final concentration of dye in the plasma after complete mixing. If the logarithm of the concentration is plotted against time, the fall-off slope forms a straight line which can be extrapolated to determine the disappearance time of dye following one circuit. This important fact, first realized by Hamilton (1932) and his group paved the way to accurate quantitative and qualitative uses of the method.

Many disease processes, both acquired and congenital, change the basic shape of the curve, but in this paper only the effects of valvular incompetence are considered with special reference to mitral regurgitation.

With a significant degree of valvular incompetence Korner and Shillingford (1955) have shown that for a given volume and forward flow the peak of concentration is lower than normal, 


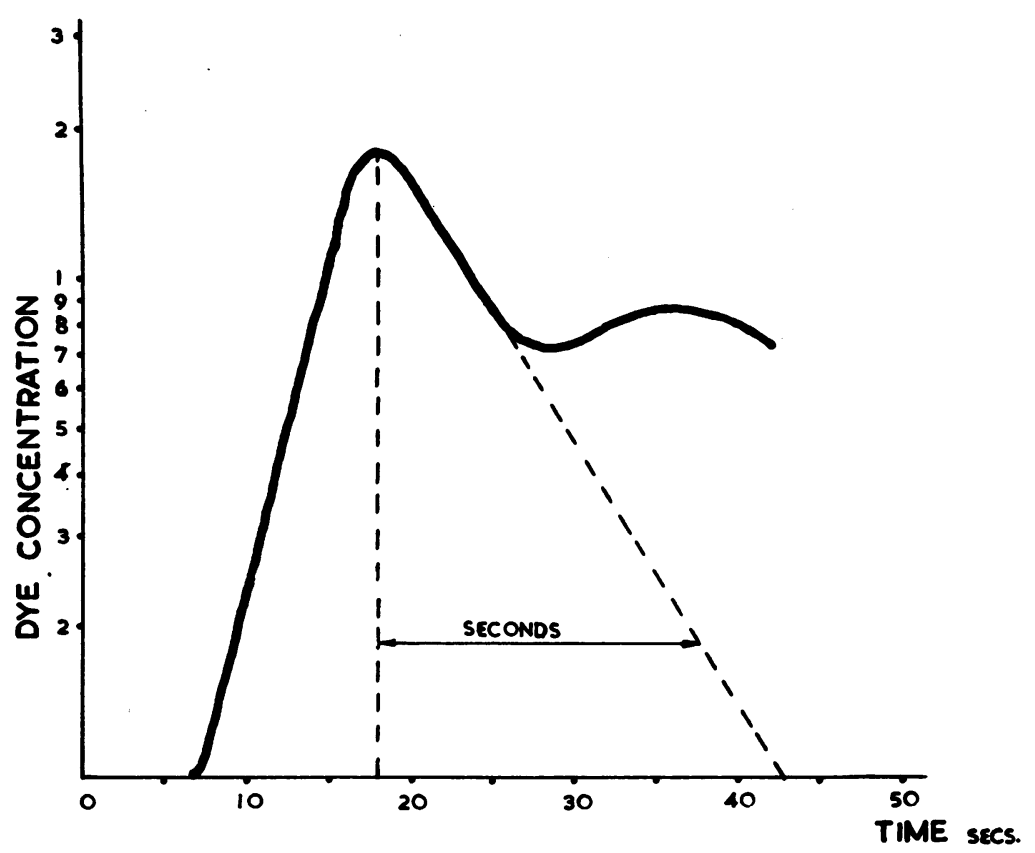

Fig. 3.-Degree of mitral incompetence assessed by the number of seconds required for a tenfold fall in concentration.

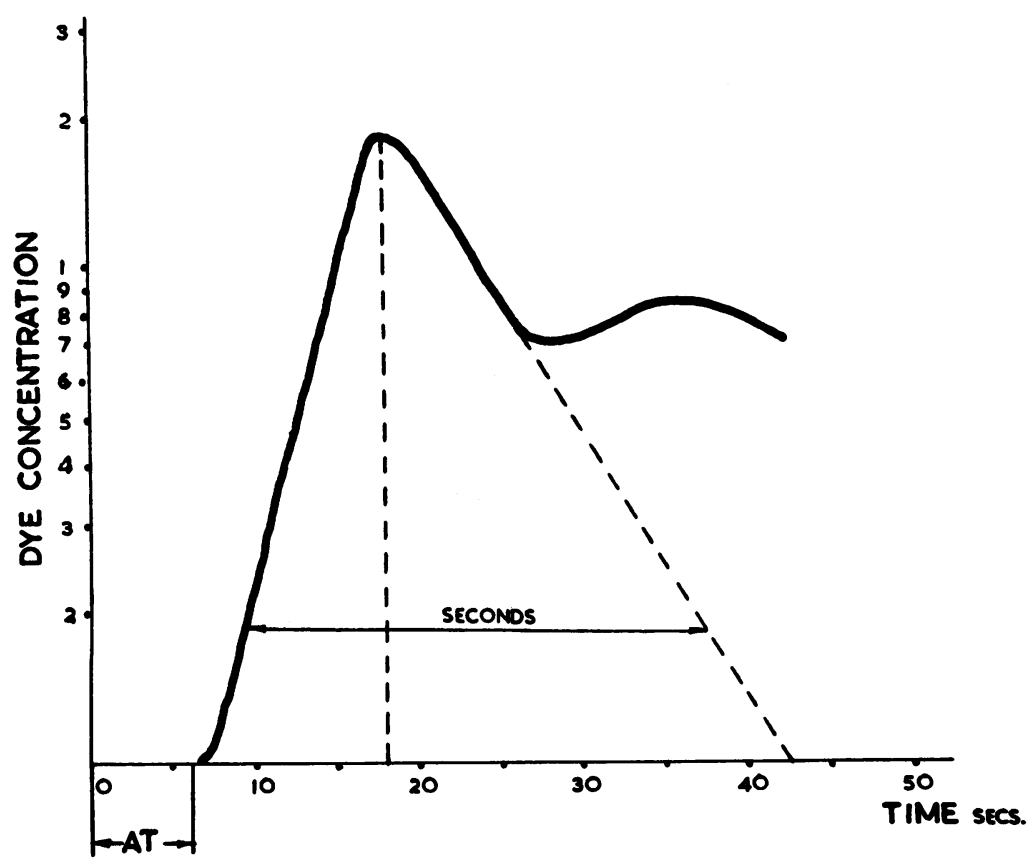

Fig. 4.-Degree of mitral incompetence assessed by the ratio of the spread of the curve at one-tenth of its height to the appearance time (A.T.) 


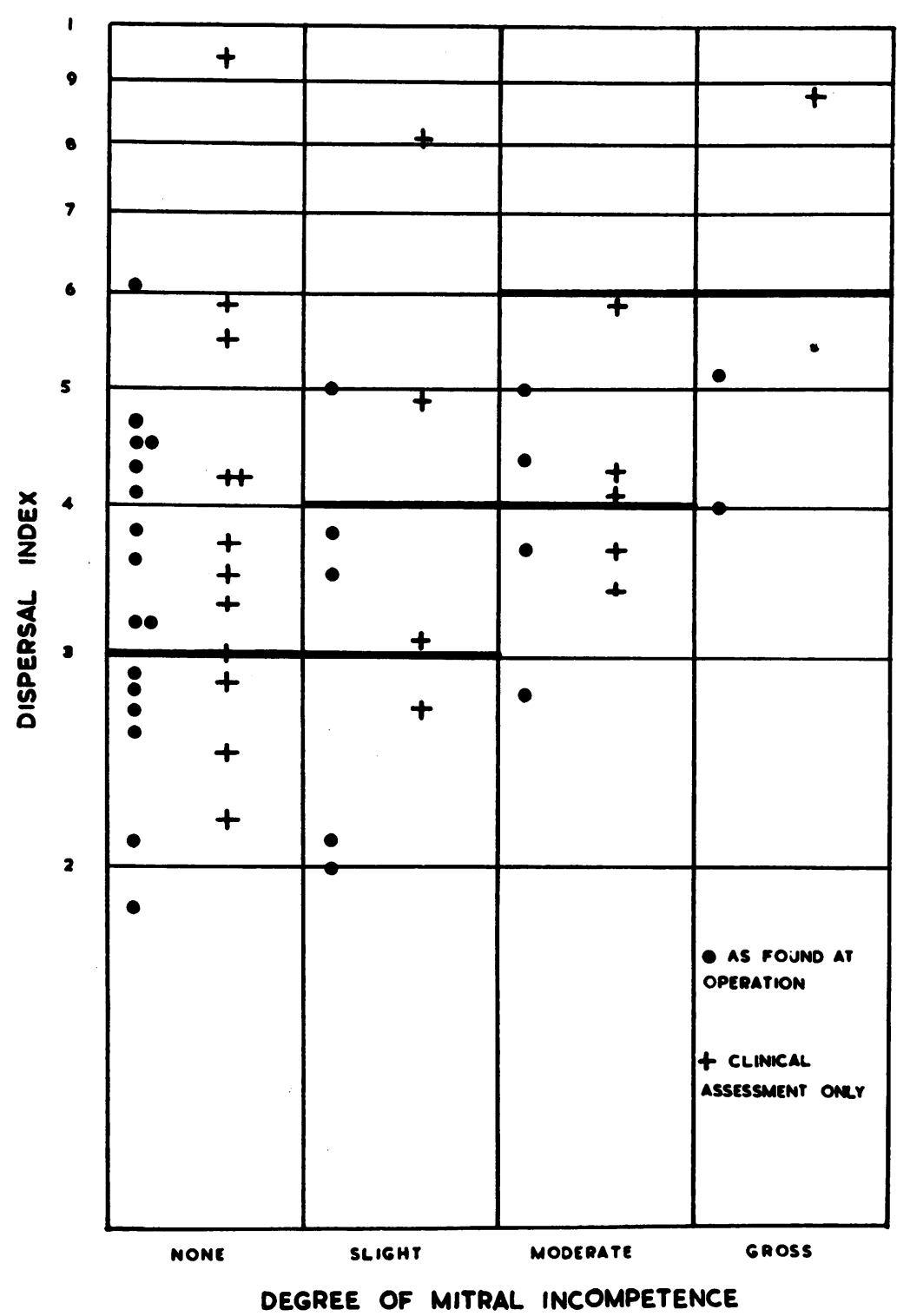

FIG. 5.-The dispersal index plotted against the degree of mitral incompetence found at operation or assessed clinically. There should be no incompetence with a dispersal index of less than 3; slight between 3-4; moderate 4-6; gross 6.

and the descending limb of the dye curve more prolonged. They further suggested (1956) that the degree of regurgitation could be determined by a series of regression equations based largely on experiments made in a model.

Woodward et al. (1957) considered (Fig. 2) that the ratio of least concentration (LC) of injected dye to peak systemic re-circulation (RC) would correlate with the degree of mitral regurgitation.

Lange and Hecht (1958) attempted qualitative and quantitative studies in mitral regurgitation based on a relationship between the appearance times at the femoral and pulmonary arteries to mean circulation times at these sites following an injection of dye into a peripheral vein. 


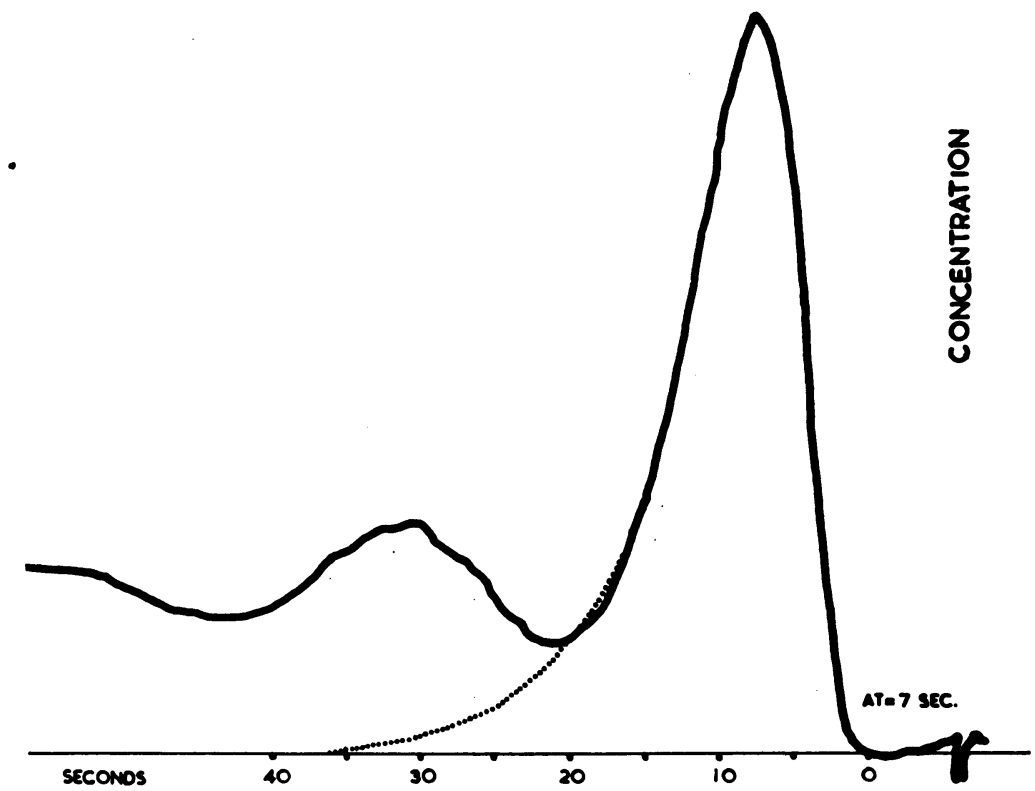

Fig. 6.-Dye dilution curve from a case of mitral stenosis with no incompetence.

(Reading from right to left.) Dispersal Index 3.0.

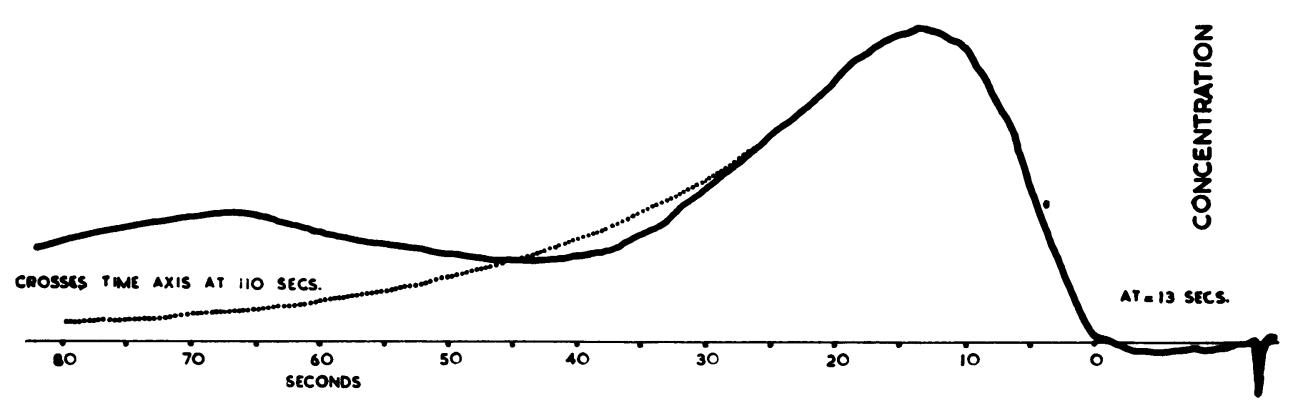

Fig. 7.-Dye dilution curve, predominant mitral incompetence. (Reading from right to left.) Dispersal index $5 \cdot 15$.

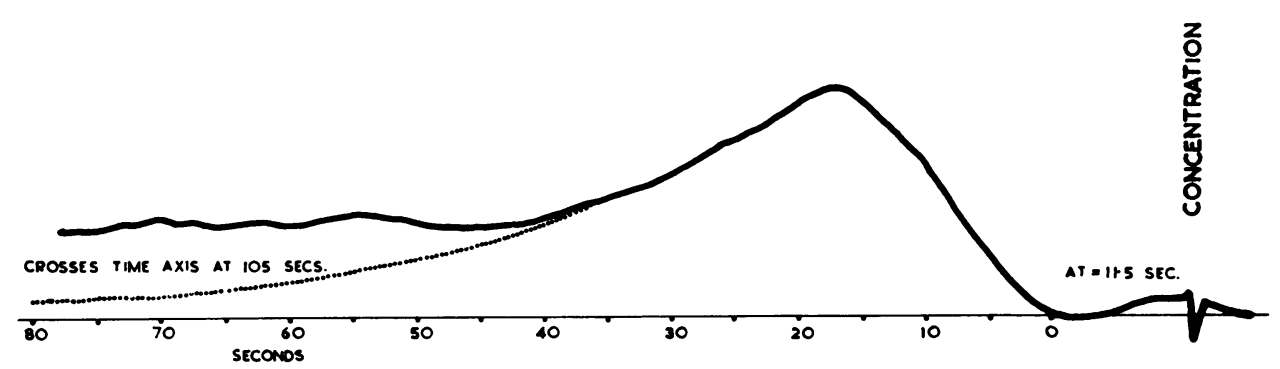

Fig. 8.-Dye dilution curve, mitral stenosis and myocardial factor. (Reading from right to left.) Dispersal Index 5.9. 
Hancock (1959) stated (Fig. 3) that the downslope expressed as the number of seconds required for a tenfold fall in concentration of dye could be used as an index of mitral regurgitation.

Recently Shillingford (1958) advocated a simple method for estimating valvular regurgitation. In the presence of valvular regurgitation spreading of the dye particles occurs independently of the effect of cardiac output or volume. The ratio of the spread of the curve at one-tenth of its height (Fig. 4) to the appearance time would be the "Regurgitant," or better the "Dispersal" Index. In Shillingford's hands, with a ratio of 3.0 or less no significant regurgitation was present, with a ratio of 4.0 or more moderate regurgitation was present, and with a ratio of 6.0 or more considerable regurgitation was present.

The advantage of this method is that the result is quickly and easily obtained. No additional calculation and sampling of blood is necessary.

\section{METHOD}

Fifty consecutive patients with mitral valve disease, but without severe aortic valve disease, had right-sided heart catheterization. Following routine measurements of pressure and oxygen saturation the catheter tip was placed in the outflow tract of the right ventricle and then slowly advanced until a pulmonary artery pulse wave was obtained. With an ear oximeter based on the design of Wood and Geraci (1949) in position, Coomassie Blue, $0.5-1.0 \mathrm{mg} . / \mathrm{kg}$., was injected rapidly into the main pulmonary artery. Balancing of the output of the red and infra-red photocells was achieved by a potentiometer, and the reduced output from the red cell caused by the passage of blue dye was led to an amplifier of chopper type capable of dealing with the direct current as alternating current for purposes of amplification. The final signal was led to a pen recorder (Cambridge Instruments Limited). The sensitivity of the recorder was such that curves of $8-10 \mathrm{~cm}$. peak concentration were obtained. Following re-plotting and extrapolation on semi-logarithmic paper, the Shillingford Index was measured.

The clinical findings, electrocardiogram, and radiological and catheter results were assessed, particular attention being paid to the presence or absence of a systolic murmur at the apex, a third heart sound, the type of apex beat and enlargement of the left ventricle. A diagnosis of the presence or absence of mitral regurgitation was made, and a clinical assessment of the severity recorded. This was compared with the dispersal index of the dye curve (Table I).

As control, the dispersal index was worked out in seven patients with normal hearts.

Twenty-three of the fifty cases of mitral valve disease came to operation, and at mitral valvotomy the degree of regurgitation found by the surgeon was noted.

\section{RESULTS}

The dispersal indices in the seven patients with normal hearts were all less than $3 \cdot 0$.

Agreement between the dispersal index on the one hand and clinical or operative findings when available on the other, was good only in those cases of gross or moderate mitral regurgitation. There were twelve examples of moderate or gross mitral incompetence, and of these eleven had a dispersal index in excess of $3 \cdot 4$, eight cases having a dispersal index of over $4 \cdot 0$. Very poor agreement, however, was found in the thirty-eight cases without any or with slight mitral regurgitation. Fig. 5 showed the effect of plotting the dispersal index of the operative and non-operative cases against the actual findings.

\section{Discussion}

As noted by Shillingford, in ideal circumstances an uncomplicated case of mitral stenosis (Fig. 6) will produce a curve with a dispersal index of 3 or less; similarly a gross case of mitral regurgitation (Fig. 7) will have a dispersal index of approximately 6.0. These patients, however, 
TABLE I

The Dispersal Index, Clinical Assessment of Mitral Incompetence and Degree of Incompetence found at Operation (Where Performed) In the 50 Cases

\begin{tabular}{|c|c|c|c|c|c|c|c|}
\hline Case No. & $\begin{array}{c}\text { Clinical } \\
\text { assessment }\end{array}$ & $\begin{array}{c}\text { Dispersal } \\
\text { index }\end{array}$ & $\begin{array}{l}\text { Operation } \\
\text { findings }\end{array}$ & Case No. & $\begin{array}{c}\text { Clinical } \\
\text { assessment }\end{array}$ & $\begin{array}{c}\text { Dispersal } \\
\text { index }\end{array}$ & $\begin{array}{l}\text { Operation } \\
\text { findings }\end{array}$ \\
\hline 1 & Nil & $3 \cdot 8$ & Nil & 26 & Moderate & $4 \cdot 3$ & Nil \\
\hline 2 & Nil & 3.0 & - & 27 & Nil & $3 \cdot 2$ & Nil \\
\hline 3 & Nil & 1.85 & Nil & 28 & Moderate & $4 \cdot 1$ & Nil \\
\hline 4 & Moderate & 5.0 & Slight & 29 & Nil & $4 \cdot 5$ & Nil \\
\hline 5 & Moderate & 4.0 & Gross & 30 & Nil & $3 \cdot 8$ & Slight \\
\hline 6 & Gross & $5 \cdot 2$ & Gross & 31 & Nil & $3 \cdot 6$ & Nil \\
\hline 7 & Slight & $2 \cdot 1$ & Slight & 32 & Moderate & $4 \cdot 1$ & - \\
\hline 8 & Moderate & $4 \cdot 0$ & - & 33 & Moderate & $4 \cdot 3$ & - \\
\hline 9 & Nil & $2 \cdot 8$ & Nil & 34 & Nil & $9 \cdot 45$ & - \\
\hline 10 & Slight & $2 \cdot 7$ & - & 35 & Nil & $6 \cdot 1$ & Nil \\
\hline 11 & Moderate & $3 \cdot 4$ & - & 36 & Slight & 4.9 & - \\
\hline 12 & Moderate & $2 \cdot 8$ & Moderate & 37 & Slight & $3 \cdot 5$ & Slight \\
\hline 13 & Slight & $8 \cdot 1$ & - & 38 & Moderate & $3 \cdot 7$ & - \\
\hline 14 & Moderate & $4 \cdot 4$ & Moderate & 39 & Nil & $5 \cdot 5$ & - \\
\hline 15 & Slight & $4 \cdot 75$ & Nil & 40 & Nil & $2 \cdot 5$ & - \\
\hline 16 & Gross & $8 \cdot 8$ & - & 41 & Slight & $3 \cdot 1$ & - \\
\hline 17 & Moderate & $2 \cdot 0$ & Slight & 42 & Moderate & $5 \cdot 0$ & Moderate \\
\hline 18 & Nil & $2 \cdot 2$ & - & 43 & Nil & $4 \cdot 2$ & - \\
\hline 19 & Nil & $3 \cdot 7$ & - & 44 & Moderate & $3 \cdot 7$ & Moderate \\
\hline 20 & Nil & $2 \cdot 9$ & Nil & 45 & Nil & $4 \cdot 5$ & Nil \\
\hline 21 & Nil & $2 \cdot 86$ & - & 46 & Nil & $3 \cdot 5$ & - \\
\hline 22 & Nil & $3 \cdot 25$ & Nil & 47 & Nil & $5 \cdot 9$ & - \\
\hline 23 & Nil & $3 \cdot 3$ & - & 48 & Nil & $4 \cdot 25$ & - \\
\hline 24 & Moderate & 5.9 & - & 49 & Nil & $2 \cdot 1$ & Nil \\
\hline 25 & Nil & $2 \cdot 7$ & Nil & 50 & Nil & $2 \cdot 6$ & Nil \\
\hline
\end{tabular}

rarely present difficulty in assessment by clinical means alone, and the dye curve therefore merely confirms what was already obvious. Unfortunately, it seems that it is in those cases where clinical doubt exists as to the degree of valvular incompetence and where additional help is required that the dispersal index is least helpful. Indeed on the basis of our results it is difficult to escape from the conclusion that grossly misleading information may be yielded by this method.

We would draw particular attention to the large number of patients with no clinical evidence of mitral regurgitation, confirmed at operation, in whom high dispersal indices were obtained (ten out of sixteen). 
TABLE II

Dispersal INDEX in 28 CASES Without Mitral INCOMPETENCE COMPARED WITH SIZE OF LEFT Atrium and Overall Cardiac Size Assessed RADIOLOGICALLY

\begin{tabular}{|c|c|c|c|}
\hline \multirow{2}{*}{$\begin{array}{l}\text { Dispersal } \\
\text { index }\end{array}$} & \multirow{2}{*}{$\begin{array}{l}\text { Clin. or Op. } \\
\text { assessment }\end{array}$} & \multicolumn{2}{|c|}{ X-ray } \\
\hline & & LA & Overall \\
\hline 1.85 & OP. & N. & N. \\
\hline $2 \cdot 1$ & OP. & + & + \\
\hline $2 \cdot 2$ & CLIN. & Sl. & N. \\
\hline $2 \cdot 5$ & CLIN. & N. & N. \\
\hline $2 \cdot 6$ & OP. & ++ & + \\
\hline $2 \cdot 7$ & OP. & Sl. & Sl. \\
\hline $2 \cdot 7$ & CLIN. & + & + \\
\hline $2 \cdot 8$ & OP. & ++ & ++ \\
\hline $2 \cdot 86$ & CLIN. & + & + \\
\hline 2.9 & OP. & ++ & ++ \\
\hline 3.0 & CLIN. & S1. & + \\
\hline $3 \cdot 2$ & OP. & + & Sl. \\
\hline $3 \cdot 25$ & OP. & ++ & + \\
\hline $3 \cdot 3$ & CLIN. & + & N. \\
\hline 3.5 & CLIN. & ++ & + \\
\hline $3 \cdot 6$ & OP. & ++ & + \\
\hline 3.7 & CLIN. & + & N. \\
\hline 3.8 & OP. & + & + \\
\hline $4 \cdot 2$ & CLIN. & ++ & ++ \\
\hline $4 \cdot 25$ & CLIN. & ++ & + \\
\hline $4 \cdot 3$ & OP. & ++ & ++ \\
\hline $4 \cdot 5$ & OP. & ++ & ++ \\
\hline $4 \cdot 5$ & OP. & ++ & ++ \\
\hline $4 \cdot 75$ & OP. & ++ & ++ \\
\hline $5 \cdot 5$ & CLIN. & ++ & + \\
\hline 5.9 & CLIN. & ++ & ++ \\
\hline $6 \cdot 1$ & OP. & +++ & + \\
\hline $9 \cdot 45$ & CLIN. & ++ & ++ \\
\hline
\end{tabular}

CLIN.$=$ Clinical assessment. OP. $=$ Operative assessment. $\quad$ N. = Normal. $\quad$ Sl.=Slight. $+=$ Moderate. $\quad++=$ Considerable. $+++=$ Gross.
The important fact is that dye curves in valvular regurgitation are deformed, but there would appear to be good reasons for believing that this is not of necessity related only to the degree of regurgitation. Conn et al. (1957) have shown that with equal grades of artificially created valvular regurgitation, quite different shaped curves can be obtained. It is probable that the deformity of the curve is produced by poor mixing of dye in the left atrium and by the end-diastolic residual volume.

In Table II, the dispersal indices of the twentyeight patients without mitral regurgitation assessed clinically and confirmed at operation in sixteen, are compared with the size of the left atrium and overall size of the heart shown radiologically. As can be readily seen those cases with the higher indices were all associated with considerable left atrial and overall cardiac enlargement. In two patients, however, with a dispersal index of 3.7 and 3.8 only moderate enlargement of the left atrium was present. Conversely, although in the main patients with less enlargement of the left atrium and heart as a whole had lower dispersal indices, this did not always hold true, for in three patients indices of $2 \cdot 6,2 \cdot 8$, and 2.9 were associated with considerable radiological enlargement.

It is thus apparent that the dispersal index must be interpreted in association with an approximation of the size of the left atrium. Using a model circulation Phinney et al. (1961) have demonstrated that mixing of dye particles is incomplete in larger atria. Shillingford (1961, personal communication) believes that under these circumstances the passage of the dye is only slightly increased so that the appearance time is not lengthened in relation to the spread of the curve.

There are, therefore, two factors of importance operating in determining the ultimate dimensions of the dye curve, namely, the presence or absence of mitral incompetence and the size of the heart.

It is probably untrue to suggest that the dispersal index is a measure of cardiac size alone but a high dispersal index may be obtained in patients with mitral stenosis without incompetence who have atrial fibrillation, an enlarged heart and a lowered cardiac output (Fig. 8), a fact I have used to confirm a myocardial factor.

While this paper has only dealt with the dispersal index of indicator dilution curves as suggested by Shillingford, the same objections presumably must apply to all other indirect indicator dilution 
techniques, for the principles underlying them are the same. What holds good for the circulation model often is not confirmed in clinical practice.

It remains to be seen whether sampling blood from the left atrium at the same time as injecting dye into the left ventricle (Kuykendall et al., 1957) will provide more accurate information about the degree of mitral regurgitation.

\section{SUMMARY}

Indirect indicator dilution techniques in the assessment of valvular incompetence are reviewed. The degree of mitral regurgitation shown by the dispersal index (Shillingford) is compared with the clinical, catheter and operative findings in fifty consecutive cases of mitral valve disease. Poor correlation was found, and the causes for this are stressed, with special reference to the size of the left atrium.

I would like to express my thanks to Dr. Samuel Oram and Dr. J. Shillingford for helpful criticism and advice in the preparation of this paper, to Mr. W. P. Cleland for the use of his operative findings, and to Miss J. Goulding and her staff for technical help in obtaining the dye curves.

\section{REFERENCES}

Clausen, D. F., and Lifson, N. (1956). Proc. Soc. exp. Biol., N. Y., 91, 11.

Conn, H. L., Jr., Heiman, D. F., Blakemore, W. S., Kuo. P. T., and Langleld, S. B. (1957). Clin. Res. Proc., 5, 165.

Dow, P. (1956). Physiol. Rev., 36, 77.

Hamilton, W. F. (1932). Amer. J. Physiol., 102, 551.

Hancock, E. W. (1959). Guy's Hosp. Rep., 108, 349.

Hering, E. (1829). Z. Physiol., 3, 85.

(1832). Z. Physiol., 5, 58.

Korner, P. I., and Shillingford, J. P. (1955). Clin. Sci., 14, 553. (1956). Clin. Sci., 15, 417.

Kuykendall, S. J., Ellis, F. H., Jr., Grindlay, J. H., and Wood, E. H. (1957). Surg. Forum, 7, 237.

Lange, R. L., and Hecht, H. H. (1958). Circulation, 18, 623.

Phinney, A. O., Jr., Cotton, K., Shillingford, J. P. (1961). Clin. Sci., 20, 1, 75.

Shillingford, J. P. (1958). Brit. Heart J., 20, 229.

Stewart, G. N. (1894). J. Physiol., 15, 1.

Taylor, S. H., and Shillingford, J. P. (1959). Brit. Heart J., 21, 497.

, and Thorp, J. H. (1959). Brit. Heart J., 21, 492.

Wood, E. H., and Geraci, J. E. (1949). J. Lab. clin. Med., 34, 387.

Woodward, E., Jr., Burchell, H. B., and Wood, E. H. (1957). Proc. Mayo Clin., 33, 517. 